\title{
Extraction of phenolic from Moroccan grape pomace: Optimization of decoction extraction of phenolic compounds using response surface methodology
}

\author{
Safae El Alami El Hassani, Anas Driouich, Hamid Mellouk, Bouchra Bejjany, Adil Dani and \\ Khalid Digua \\ Laboratory of Process Engineering and Environment, Faculty of Science and Technology Mohammedia, \\ Hassan II University, BP 140 Mohammedia, Morocco
}

\begin{abstract}
The present study focuses on the optimization of the parameters to extract phenolic products by decoction and the quantification of these compounds from grape pomace, using a central experimental design. The antioxidant activity of methanolic extracts from grape skin grown in Morocco was evaluated. The grapes variety is "Michael Paleiri", it is a black variety with pips, and they are from the region of Benslimane. The total phenolic compounds contents were determined by the Folin-Ciocalteu method. The optimization suggested that extraction with methanol for $29 \mathrm{~min}$, at $60{ }^{\circ} \mathrm{C}$ were the best solutions for this combination of variables.

The largest amount obtained was $1042.06 \mathrm{mg} \mathrm{EGA} / \mathrm{g} \mathrm{DW}$. The antioxidant activity is carried out by the radical scavenging method 1,1-diphenyl-2-picryl hydrazyl $\left(\mathrm{DPPH}^{\circ}\right)$ and the ferric iron reduction capacity (FRAP). The DDPH inhibition capacity reached $20.78 \%$, compared with $15.22 \%$ of a BHT solution at $0.001 \mathrm{~g} / \mathrm{L}$. A significant relationship between antioxidant capacity and total phenolic content is evident $\left(\mathrm{R}^{2}=0.994\right)$. These results demonstrate that methanol extracts from the waste from grapes grown in Morocco could be used as potential sources of natural extracts rich in phenolic compounds and endowed with significant antioxidant activity.
\end{abstract}

Keywords: Grape pomace, Phenolic compounds, Antioxidant activity, Response surface methodology.

\section{Introduction}

There is growing interest in the use of residues generated by the wine and grape industries. In recent years, grape pomace is used as soil conditioner and fertilizer, as an adsorbent for heavy metals. Moreover, it is used in the food industry and the production of pullulan ${ }^{1}$. The skins of grapes are the only industrial source for tartaric acid production which is used as an additive in medicines and cosmetics, as acidulant and compound in soft drinks ${ }^{2}$. In particular, waste from vineyards could be an alternative source for obtaining natural antioxidants without any negative effects in comparison to synthetic antioxidants. Grape pomace represents a rich source in bioactive molecules with the high added value that can be applied in many industries ${ }^{3}$. Moreover, it is characterized by high levels of a total phenolic compound and total flavoinds ${ }^{4,5}$. For this reason, large quantities of phenolic compounds remain in the by-products of wine and grape juice, and there is a great interest in exploiting this type of grape by-products to obtain potentially bioactive phenolic compounds ${ }^{5,8}$.

Antioxidants are potent free radical scavengers and serve as inhibitors of neoplastic processes ${ }^{9}$ and

*Corresponding author: Hamid Mellouk

Email address: hmellouk17@gmail.com

DOI: http://dx.doi.org/10.13171/mjc76198121610hm allow the body to fight against aggressions of oxygen which are at the origin of a large number of diseases, which is attracting more and more interest in the prevention and treatment of cancer ${ }^{10}$. Furthermore, antioxidants have anti-inflammatory activity ${ }^{11,12}$, cardiovascular 13,15, neurodegenerative-protective activities ${ }^{16}$ antineoplastic and antihepatotoxic ${ }^{17}$. Various antioxidants are provided to cells through diet; vitamin $\mathrm{E}$ wich is present in grape seeds can prevent lipid peroxidation of plasma membrane ${ }^{18}$.

Several methods are used for the extraction of polyphenolic compounds (TPC). According to Soural et al. (2015) ${ }^{19}$, extraction of TPC from grape can give different stilbene yields according to the process employed using several organic solvents. The best yields are obtained by decoction with methanol; other innovative processes have been carried out, such as fluidized bed extraction or reflux extraction, which give similar yields of the decoction, but new techniques such as accelerated solvent extraction or assisted extraction by microwave give higher yields of phenolic compounds.

However, there is no single solvent or method optimal to extract all TPC from grape pomace, TPC

Received June 5, 2018

Accepted July 2 , 2018

Published December 16, 2018 
obtained by maceration in red pomace extract was higher than TPC in white pomace extract ${ }^{20}$.

Our study aims to optimize the phenolic compounds extraction parameters by decoction from the table grape skins used in the manufacture of juices as well as to assess their content of essential bioactive compounds, hence their antioxidant power. The extraction is carried out in the presence of methanol, and extracts are analysed in order to quantify their concentration of total phenolic compounds (TPC) as well as their antioxidant and antiradical properties.

\section{Material and Methods}

\section{Plant material}

The black grapes of "MichealPaleiri" variety are harvested in the region of Benslimane in Morocco in September 2016. The berry skins are separated manually from the pulp and then dried at $40^{\circ} \mathrm{C}$ for 48 hours and then ground and screened (particle size $<350 \mu \mathrm{m})$. The obtained powder is homogenised, sifted and stored at $5^{\circ} \mathrm{C}$ in the dark until use. The humidity content of the powder was $13 \%$.

\section{Extraction}

To establish an optimal method for the quantitative extraction of polyphenols from grape skin, we used a central composite design.

In a bottle, $20 \mathrm{~mL}$ of solvent is added to $2 \mathrm{~g}$ of grape skin powder; the whole is brought to a temperature between $26^{\circ} \mathrm{C}$ and $66^{\circ} \mathrm{C}$ in a water bath for a period ranging from $3 \mathrm{~min}$ to $182 \mathrm{~min}$. The extracts are then filtred with a paper filter and washed with $5 \mathrm{~mL}$ of the same solvent and then transferred to new tubes and stored at $5^{\circ} \mathrm{C}$ until use (Figure 1).

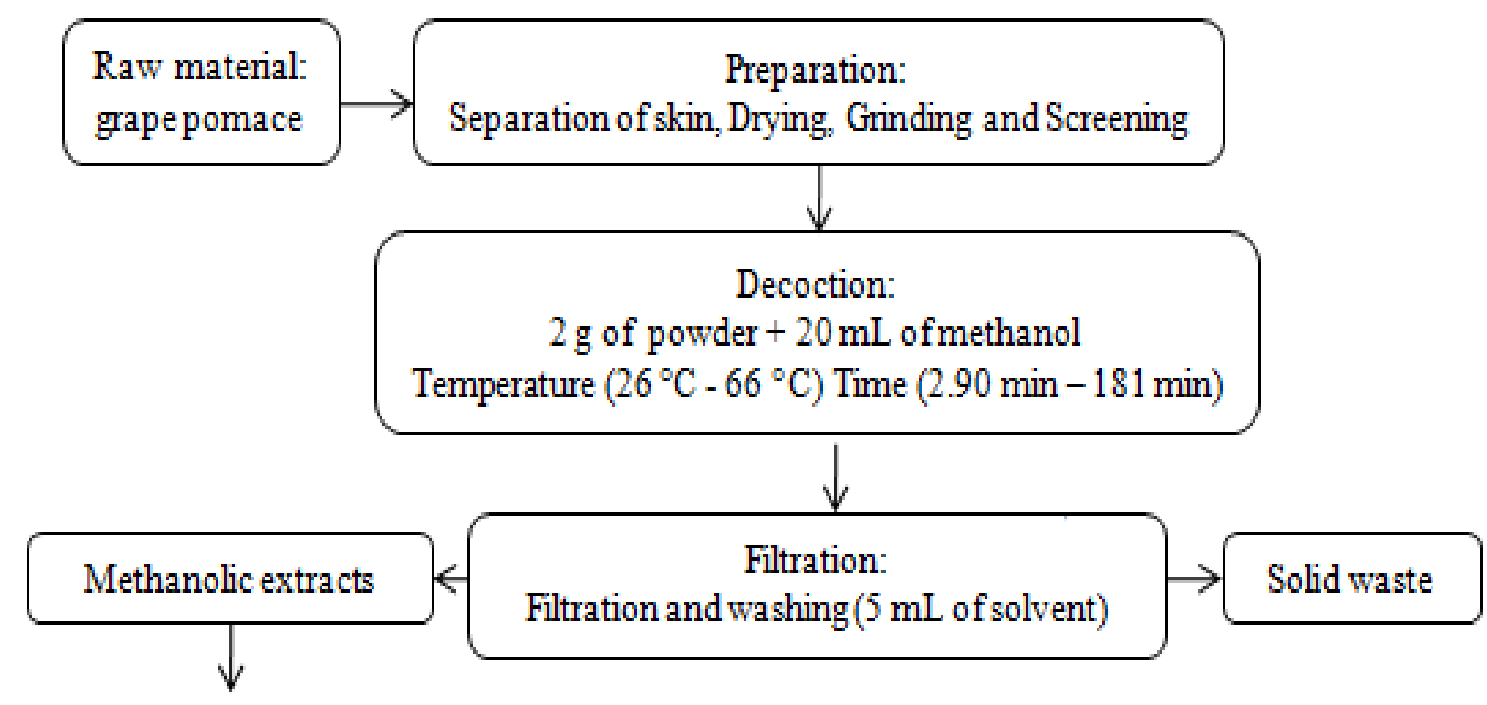

\section{Analyzes: \\ TPC: Determination of phenolic compounds (TPC) by Folin-Ciocalteu method \\ DPPH: Measurement of antioxidant activity of extracts by Free Radical Trapping DPPH ${ }^{\circ}$ Test FRAP: Reducing power of iron tested by measuring the reducing power of feric iron in extracts}

Figure 1. General study protocol

\section{Total Phenolic Compounds}

The total polyphenols (TPC) in the grape skin extracts are determined using the spectrophotometric method of Folin-Ciocalteu according to the literature 21,22 , using gallic acid as a standard.

$10 \mu \mathrm{L}$ of extract or one of the concentrations of the standard range are added to $1.58 \mathrm{~mL}$ of distilled water, and then $100 \mu \mathrm{L}$ of the Folin-Ciocalteu reagent are finally added. The obtained mixture is left for 5 min at room temperature, and then $300 \mu \mathrm{L}$ of the $\mathrm{Na}_{2} \mathrm{CO}_{3}$ solution are added. The whole is incubated in the dark and at room temperature for two hours. The absorbance is read at $765 \mathrm{~nm}$. The same procedure is repeated for all standard gallic acid solutions (40$1000 \mathrm{mg} / \mathrm{L}$ ), and a standard curve is obtained. TPC in grape skin extracts was expressed as milligram of Gallic Acid equivalent (GAE) per gram of the dry extract averaged from tree parallel measurements.

\section{Measurement of the scavenging power of the DPPH radical}

The 2,2-diphenyl-1-picrylhydrazyl ( $\alpha, \alpha$-diphenyl picrylhydrazyl) (DPPH) was one of the first free radicals used to study the antioxidant structureactivity relationship of phenolic compounds ${ }^{23,24}$. The antioxidant activity of the extract is evaluated regarding the capability of scavenging free radicals of 
DPPHformed, according to a method described by Lue et al. (2010) ${ }^{25}$.

$10 \mu \mathrm{L}$ of the extract is added to $5 \mathrm{~mL}$ of the DPPH solution at $0.4 \mathrm{~g} / \mathrm{L}$, the whole is incubated for $30 \mathrm{~min}$ in the dark, and at room temperature, the absorbance is measured at $517 \mathrm{~nm}$. A blank is prepared by mixing $10 \mu \mathrm{L}$ of methanol with $5 \mathrm{~mL}$ of the DPPH solution. The DPPH radical is diluted in methanol at a concentration of $0.04 \mathrm{~g} / \mathrm{L}$ and kept away from light before use. Reduction of the free radical DPPH by an antioxidant is monitored by UV-Vis spectrophotometer, measuring the absorbance decrease at $517 \mathrm{~nm}$ caused by the antioxidants. In the presence of the free radical scavengers, the DPPH with violet color is reduced to DPPH with yellow color ${ }^{26}$. BHT is used as positive control. The scavenging activity was calculated as follows:

\section{I\% $=(($ A Control - A sample $) /$ A Control $) * 100$}

Where A Control is the absorbance of blank and A Sample is the absorbance of test extract or positive control. Tests were carried in triplicate.

\section{Ferric Reducing Antioxidant Power}

The ferric reducing antioxidant power(FRAP) is determined according to the method previously described by Oyaizu (1986) ${ }^{27}$. The reduction of $\mathrm{Fe}^{3+}$ to $\mathrm{Fe}^{2+}$ is determined by measuring the absorbance of the Prussian blue complex of Perl. $1 \mathrm{~mL}$ of the methanolic extracts are mixed with $2.5 \mathrm{~mL}$ of phosphate buffer $(0.2 \mathrm{M}, \mathrm{pH}=6.6)$ and $2.5 \mathrm{~mL}$ of $1 \%$ potassium ferricyanide $\left[\mathrm{K}_{3} \mathrm{Fe}(\mathrm{CN})_{6}\right]$. The mixture is incubated at $50{ }^{\circ} \mathrm{C}$ for $20 \mathrm{~min}$. Then an aliquot of 2.5 $\mathrm{mL}$ of $10 \%$ trichloroacetic acid is added to the mixture, which is then centrifuged at $3000 \mathrm{rpm}$ for 30 min. $2.5 \mathrm{~mL}$ of supernatant is mixed with $2.5 \mathrm{~mL}$ of distilled water and $0.5 \mathrm{~mL}$ of $0.1 \% \mathrm{FeCl}_{3}$. The absorbance is measured at $700 \mathrm{~nm}$ against a blank containing the same reagents by replacing the extract with distilled water. A greater absorbance of the reaction mixture indicates an increased reduction power ${ }^{28,29}$. Ascorbic acid is used as positive control. Tests were carried in triplicate.

\section{Experimental design and statistical analysis}

Optimizing parameters of phenolic compounds extraction from grape pomace is attained by using the response surface methodology (RSM). RSM is a collection of mathematical and statistical techniques useful for developing, improving and optimizing the process and it can be used to evaluate the relative significance of several affecting factors even in the presence of complex interactions. The objective of RSM is to determine the optimum operational conditions and to determine the field that satisfies the operating specifications. The application of this methodology in the extraction of bioactive molecules can determine the optimum for tree responses, total phenolic compounds yield, antioxidant activity by the radical scavenging method (DPPH) and the ferric iron reduction capacity (FRAP).

The experimental data of the TPC, DPPH and FRAP assays were expressed by the mean and standard deviation. To evaluate statistical results, ANOVA and Fisher Test were used. $\mathrm{p} \leq 0.05$ values are considered statistically significant.

\section{Results and Discussion}

We used response surface methodology to optimize extraction parameters of bioactive molecules in the grape skin extracts. In order to carry out our experiments, we adopted a central composite design with two parameters, the heating temperature in ${ }^{\circ} \mathrm{C}$ and the time in min of the decoction (Table 1). Thirteen experiments with five central points for replications and eight points representing the possible combinations between the two parameters levels are obtained (Table 2). To study the parameters of the responses, total phenolic compounds (TPC), antioxidant power (Scavenging power of the DPPH) and the antiradical power (FRAP), we used Statgraphics Centurion Software; (version1.6).

These calculations allow us to process results by analysing the variance, estimating direct effects, interactions and quadratic effects of extraction parameters. The objective is to determine the optimum parameters to obtain an extract with the best yield of bioactive molecules and greater antioxidant power.

Table 1. Coded levels for the independent variables used in the development of experimental data.

\begin{tabular}{|c|c|c|c|c|c|}
\hline & \multicolumn{8}{c|}{ Coded levels } \\
\hline Temperature $\left({ }^{\circ} \mathrm{C}\right)$ & $-\boldsymbol{\alpha}$ & $\mathbf{- 1}$ & $\mathbf{0}$ & $\mathbf{+ 1}$ & $\mathbf{+ \alpha}$ \\
\hline Decoction time (min) & 26 & 32 & 46 & 60 & 66 \\
\hline
\end{tabular}


Table 2. Central composite design presented in standard order.

\begin{tabular}{|c|c|c|}
\hline & Coded variables & $\mathbf{X}_{\mathbf{2}}$ \\
\hline 1 & $\mathbf{X}_{\mathbf{1}}$ & 0 \\
\hline 2 & $-\alpha$ & -1 \\
\hline 3 & -1 & 0 \\
\hline 4 & $+\alpha$ & $+\alpha$ \\
\hline 5 & 0 & -1 \\
\hline 6 & +1 & 0 \\
\hline 7 & 0 & +1 \\
\hline 8 & +1 & 0 \\
\hline 9 & 0 & 0 \\
\hline 10 & 0 & +1 \\
\hline 11 & -1 & $-\alpha$ \\
\hline 12 & 0 & 0 \\
\hline 13 & 0 & 0 \\
\hline
\end{tabular}

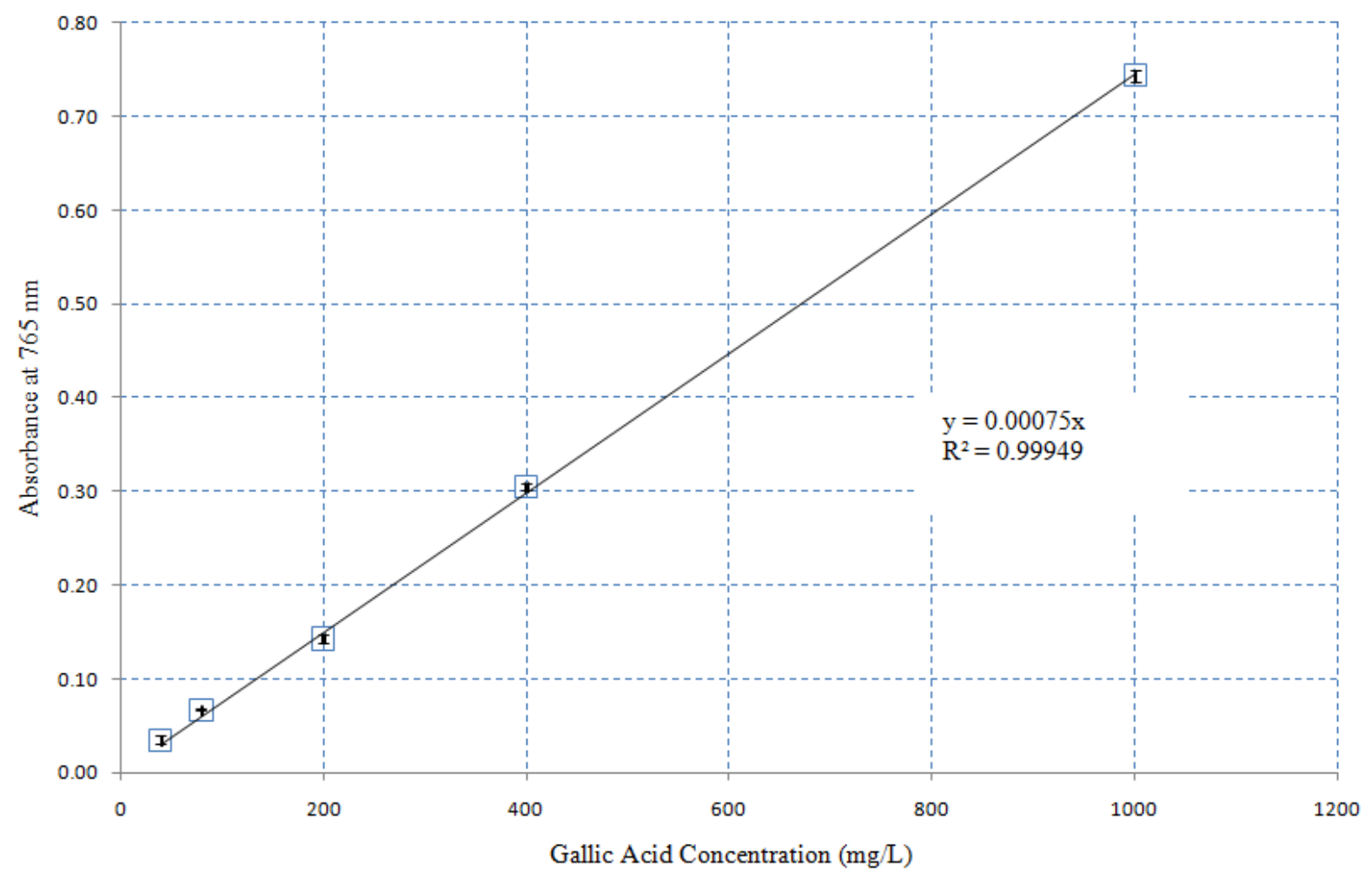

Figure 2. Calibration of gallic acid.

The responses (Y) are related to the independent variables coded $\mathrm{X}_{\mathrm{i}}$ and $\mathrm{X}_{\mathrm{j}}$ according to the second order polynomial expressed in equation (1), with $\beta_{0}$ the intercept coefficient, $\beta_{\mathrm{i}}$ the linear terms, $\beta_{\mathrm{ii}}$ the quadratic terms, $\beta_{\mathrm{ij}}$ the interaction terms. The Fisher test for the analysis of variance (ANOVA) is carried out on experimental data, which makes it possible to estimate the statistical significance of the proposed models.

$\mathbf{Y}=\boldsymbol{\beta}_{\mathbf{0}}+\sum_{\mathrm{i}=\mathbf{1}}^{\mathrm{n}} \boldsymbol{\beta}_{\mathrm{i}} \mathbf{X}_{\mathbf{i}}+\sum_{\mathrm{i}=\mathbf{1}}^{\mathrm{n}} \boldsymbol{\beta}_{\mathrm{ii}} \mathbf{X}^{\mathbf{2}}{ }_{\mathrm{i}}+\sum_{\mathrm{i} \neq \mathbf{j}} \boldsymbol{\beta}_{\mathrm{ij}} \mathbf{X}_{\mathbf{i}} \mathbf{X}_{\mathbf{j}}$

For the determination of the total polyphenols, the $\mathrm{UV}-\mathrm{Vis}$ spectrophotometer made it possible to 
quantify the level of polyphenols present in methanolic extracts of grape skins, by Folin-Ciocalteu method. Calibration curve is established using different concentrations of Gallic Acid from a stock solution of $1 \mathrm{~g} / \mathrm{L}$. It made it possible to estimate the content of phenolic compounds in extracts, via linear equation $\mathrm{y}=0.00075 \mathrm{x}$ of gallic acid calibration curve (Figure 2).

The complete design matrix, as well as the experimental values, total phenolic compounds, the DPPH scavenging activity and FRAP, are given in Table 3.

Regression analysis is carried out to establish mathematical models with experimental data aiming Yield of TPC:

$Y=54.0055+25.7427 X_{1}+1.4648 X_{2}+0.0146 X_{1} X_{2}-0.2119 X_{1}{ }^{2}-0.0066 X_{2}^{2}$

Scavenging power of the DPPH:

$Y=3.4970+0.1605 X_{1}+0.0865 X_{2}-0.0013 X_{1} X_{2}+0.0015 X_{1}{ }^{2}-0.0001 X_{2}^{2}$

Antioxidant Power FRAP:

$Y=2.32274+0.01375 X_{1}-0.00051 X_{2}+0.000001 X_{1} X_{2}-0.00011 X_{1}^{2}-0.000002 X_{2}^{2}$

Table 3. Experimental data and responses (TPC, DPPH and FRAP in grape skin extracts) obtained with different combinations of temperature $\left(\mathrm{X}_{1}\right)$ and decoction time $\left(\mathrm{X}_{2}\right)$ used in the design of the central composite randomised plane.

\begin{tabular}{|c|c|c|c|c|c|c|c|c|}
\hline \multirow{2}{*}{$\mathrm{N}^{\circ}$} & \multirow{2}{*}{$\mathrm{T}\left({ }^{\circ} \mathrm{C}\right)$} & \multirow{2}{*}{$\begin{array}{l}\text { Duration } \\
\text { (min) }\end{array}$} & \multicolumn{2}{|c|}{ TPC (mg EGA/g MS) } & \multicolumn{2}{|c|}{ DPPH $(\%)$} & \multicolumn{2}{|c|}{ FRAP (Abs.) } \\
\hline & & & Exp. & Estim. & Exp. & Estim. & Exp. & Estim. \\
\hline 1 & 26 & 92 & $642.95+/-0.00$ & 697.11 & $12.88+/-0.85$ & 12.89 & $2.58+/-0.03$ & 2.56 \\
\hline 2 & 32 & 29 & $758.84+/-4.10$ & 711.26 & $13.11+/-0.21$ & 11.41 & $2.61+/-0.02$ & 2.64 \\
\hline 3 & 66 & 92 & $1000.89+/-$ & 997.71 & $19.48+/-0.24$ & 20.06 & $2.67+/-0.00$ & 2.70 \\
\hline 4 & 46 & 181 & $936.91+/-0.00$ & 960.23 & $18.26+/-0.15$ & 16.30 & $2.61+/-0.02$ & 2.63 \\
\hline 5 & 60 & 29 & $905.15+/-4.31$ & 898.06 & $20.78+/-0.10$ & 18.75 & $2.75+/-0.00$ & 2.74 \\
\hline 6 & 46 & 92 & $893.51+/-3.38$ & 930.48 & $15.26+/-0.13$ & 15.90 & $2.60+/-0.01$ & 2.68 \\
\hline 7 & 60 & 155 & $1042.06+/-$ & 1039.99 & $16.96+/-0.09$ & 18.05 & $2.79+/-0.01$ & 2.67 \\
\hline 8 & 46 & 92 & $939.60+/-0.00$ & 930.48 & $15.76+/-0.14$ & 15.90 & $2.77+/-0.01$ & 2.68 \\
\hline 9 & 46 & 92 & $893.96+/-0.00$ & 930.48 & $16.08+/-0.15$ & 15.90 & $2.74+/-0.01$ & 2.68 \\
\hline 10 & 32 & 155 & $844.3+/-1.34$ & 801.68 & $13.70+/-0.17$ & 15.19 & $2.65+/-0.00$ & 2.57 \\
\hline 11 & 46 & 3 & $767.79+/-1.34$ & 795.94 & $11.52+/-0.37$ & 14.07 & $2.75+/-0.01$ & 2.72 \\
\hline 12 & 46 & 92 & $934.23+/-9.40$ & 930.48 & $16.85+/-0.33$ & 15.90 & $2.66+/-0.00$ & 2.68 \\
\hline 13 & 46 & 92 & $989.71+/-3.87$ & 930.48 & $\begin{array}{c}15.57+/-0 . \\
11\end{array}$ & 15.90 & $2.66+/-0.01$ & 2.68 \\
\hline
\end{tabular}

Data are presented as mean $+/-\mathrm{SD}, \mathrm{n}=3$ experiments

According to the results of Table 4, linear terms, temperature and time of extraction are highly significant for the TPC yield $(\mathrm{P}=0.0003$ and $\mathrm{P}=0.0092$ respectively). However, the interaction between temperature and extraction time is significant $(\mathrm{P}=0.0483)$, in the other hand square effects of temperature and time are not significant
( $\mathrm{P}=0.5923$ and $\mathrm{P}=0.1739$ respectively). For $\mathrm{DPPH}$ test, we found that just linear term of temperature is highly significant $(\mathrm{P}=0.0054)$. However, FRAP test process parameters do not have a significant statistic effect. F-values were higher compared to F- theoretical reed on Fischer table. 
Table 4. Estimated regression coefficients and corresponding F-value and P-value for the yield of TPC, DPPH and FRAP.

\begin{tabular}{|c|c|c|c|c|c|c|}
\hline & Term & Coefficient & Sum of square & F-ratio & P-value & Meaning \\
\hline \multirow[t]{6}{*}{ TPC } & Constant & 54.0055 & --- & --- & --- & --- \\
\hline & $\mathrm{X}_{1}$ & 25.7427 & 90370.70000 & 42.98 & 0.0003 & $* * *$ \\
\hline & $\mathrm{X}_{2}$ & 1.4648 & 26627.50000 & 12.66 & 0.0092 & $* *$ \\
\hline & $\mathrm{X}_{1} \mathrm{X}_{2}$ & 0.0146 & 11997.00000 & 5.71 & 0.0483 & $*$ \\
\hline & $\mathrm{X}_{1}^{2}$ & -0.2119 & 661.77600 & 0.31 & 0.5923 & NS \\
\hline & $\mathrm{X}_{2}^{2}$ & -0.0066 & 4816.42000 & 2.29 & 0.1739 & NS \\
\hline \multirow[t]{6}{*}{ DPPH } & Constant & 3.49701 & --- & --- & --- & --- \\
\hline & $\mathrm{X}_{1}$ & 0.1605 & 51.32770 & 15.71 & 0.0054 & $* *$ \\
\hline & $X_{2}$ & 0.0865 & 4.96405 & 1.52 & 0.2576 & NS \\
\hline & $\mathrm{X}_{1} \mathrm{X}_{2}$ & -0.00125 & 0.57951 & 0.18 & 0.6863 & NS \\
\hline & $\mathrm{X}_{1}^{2}$ & 0.00147 & 4.86202 & 1.49 & 0.2621 & NS \\
\hline & $\mathrm{X}_{2}^{2}$ & -0.0001 & 0.88352 & 0.27 & 0.6191 & NS \\
\hline \multirow[t]{6}{*}{ FRAP } & Constant & 2.32274 & --- & --- & --- & --- \\
\hline & $\mathrm{X}_{1}$ & 0.01375 & 0.01980 & 3.95 & 0.0872 & NS \\
\hline & $\mathrm{X}_{2}$ & -0.00051 & 0.00159 & 0.32 & 0.5905 & NS \\
\hline & $\mathrm{X}_{1} \mathrm{X}_{2}$ & 0.00000 & 0.00319 & 0.64 & 0.4511 & NS \\
\hline & $\mathrm{X}_{1}^{2}$ & -0.00011 & 0.00001 & 0 & 0.9728 & NS \\
\hline & $\mathrm{X}_{2}^{2}$ & 0.00000 & 0.00039 & 0.08 & 0.7865 & NS \\
\hline
\end{tabular}

$* * *$ : significant to probability $\alpha=0.1 \%\left(\mathrm{~F}_{\text {theorical }}(1,7)=29.25\right)$

$* * \quad$ : significant to probability $\alpha=1 \%\left(\mathrm{~F}_{\text {theorical }}(1,7)=12.25\right)$

*** : significant to probability $\alpha=5 \%\left(\mathrm{~F}_{\text {tehorical }}(1,7)=5.59\right)$

NS : not significant

With $\mathrm{F}(v 1, v 2)$ is the function of Fisher at $v 1$ and $v 2$ degrees of freedom for a probability $\alpha$.

According to the Pareto diagrams (Figure 3), temperature and extraction time influence together very significantly the TPC yield, as well as their antioxidant power by testing the free radical $\mathrm{DPPH}^{\circ}$, and reducingFRAP iron.

The three-dimensional profiles of multiple nonlinear regression models (Figure 4) are used to illustrate the linear and quadratic effects of the two key variables as well as the interaction effects between temperature and extraction time on the extraction yield of total phenolic compounds, the per cent inhibition of DPPH and FRAP obtained from the table grape skins.

The most influential effects on TPC yield are the linear terms of temperature $\left(\mathrm{X}_{1}\right)$ and extraction time $\left(\mathrm{X}_{2}\right)$. Figure 4 clearly shows that the TPC yield increases linearly as the temperature and extraction time increase. This increase is also underlined by Lazar (2016), solubility and diffusivity of TPC increase at high extraction temperature improving the mass transfer. However, high temperature $\left(>60^{\circ} \mathrm{C}\right)$ can cause thermal degradation ${ }^{30}$. According to Gambuti (2009) ${ }^{31}$, TPC yield of grape skins extracts was influenced by contact time and solvent, the maximum yield of (+ )-catechine, (-)-epicatechin and flavan-3-ols, was reached at 24 hours of extraction time. However, caffeic acid reached its maximum yield at the fourth day of extraction, but gallic acid yield increase during extraction time which is due to co-pigmentation phenomena and to nonenzymatic autoxidation of vicinal dihydroxyphenols. High temperature favors the extraction process by improving the solubility of phenolic compounds, and the mass transfer rate and weakening plant tissue ${ }^{32,33}$. 


\section{Standardized Pareto Chart for DPPH}

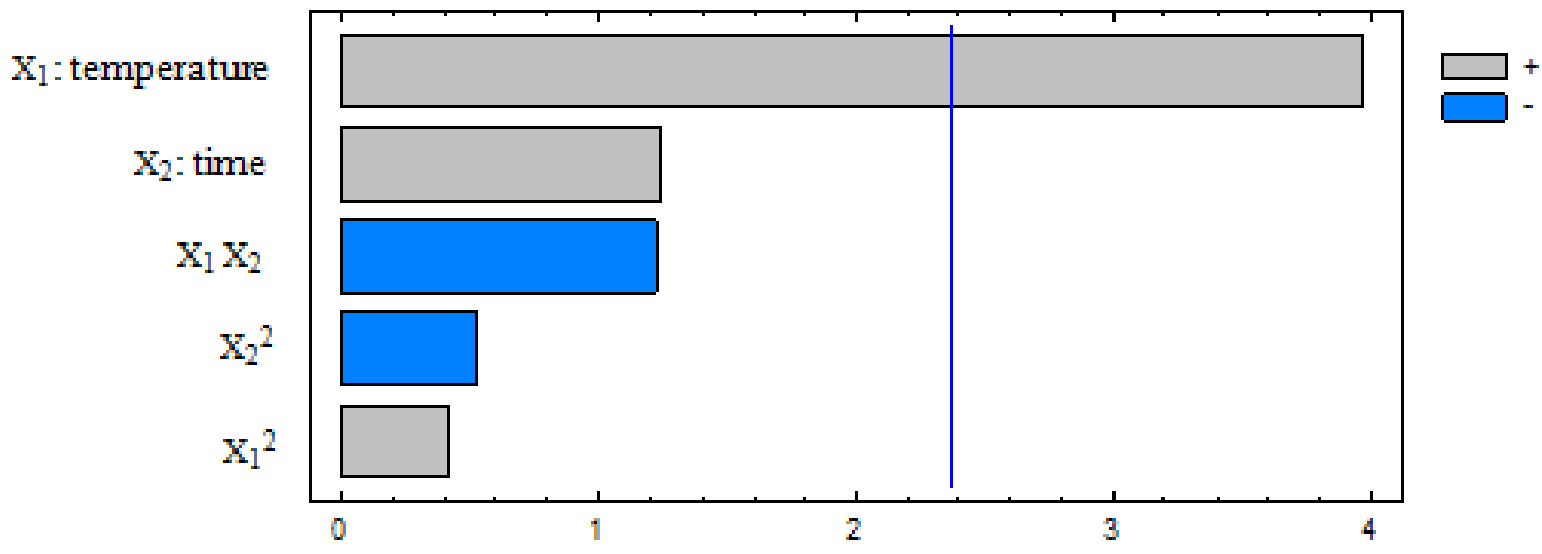

Standardized Pareto Chart for TPC

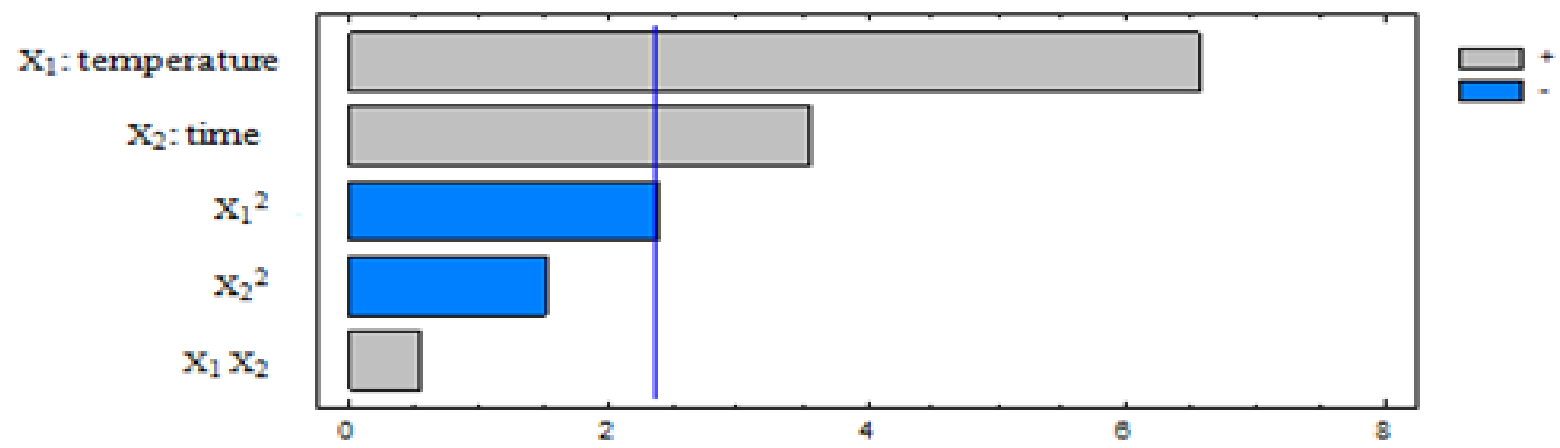

Standardized Pareto Chart for FRAP

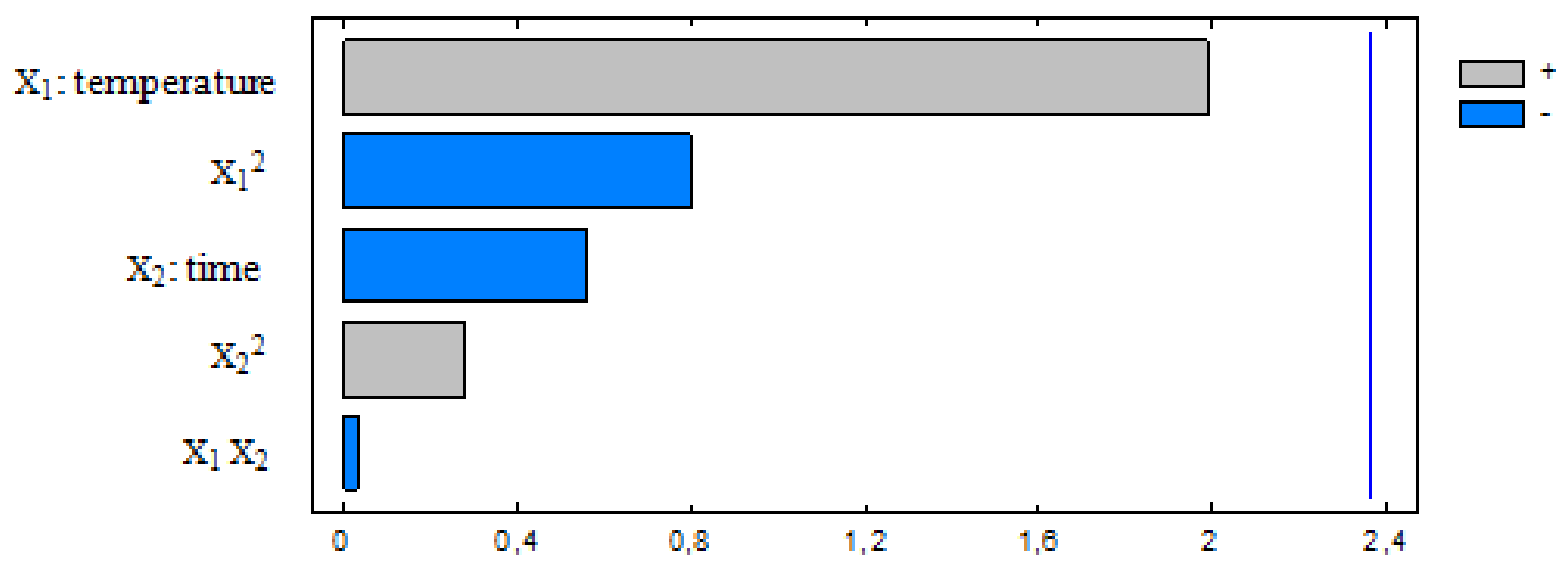

Figure 3. Pareto charts of standardized effects of each term in the model divided by its standard error for three response variables: TPC (top), DPPH (center) FRAP (bottom) in grape skins. 

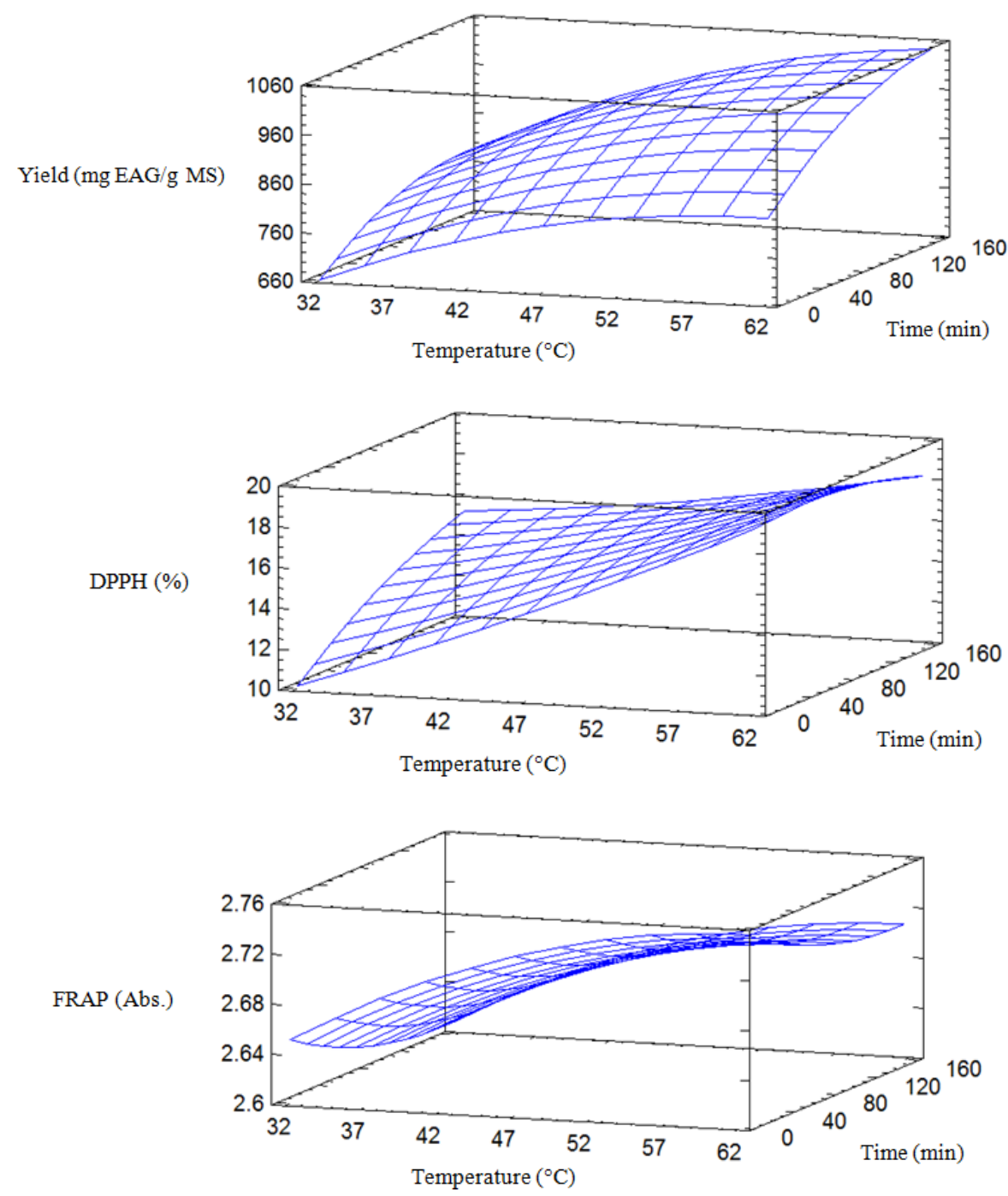

Figure 4. Plot of TPC, DPPH and FRAP response surface expressed as a function of temperature and extraction time for grape pomace

The interaction between the temperature and the extraction time is also visible in figure 5 when the temperature rises from its low level $\left(32^{\circ} \mathrm{C}\right)$ to its high level $\left(60{ }^{\circ} \mathrm{C}\right)$, a small variation in total phenolic compounds, from $710 \mathrm{mg}$ EAG / g MS to $890 \mathrm{mg}$ EAG / g MS, is observed for one extraction time set at $29 \mathrm{~min}$. Conversely, a strong evolution is observed, from $790 \mathrm{mg}$ EAG / g MS to $1040 \mathrm{mg}$ EAG / g MS for an extraction time set at $155 \mathrm{~min}$. For the inhibitory power of the DPPH radical, it is found that when the temperature is set at $32{ }^{\circ} \mathrm{C}$ and the duration increases from $29 \mathrm{~min}$ to $155 \mathrm{~min}$, the inhibition percentage inhibition increases from $11.5 \%$ to $15 \%$. On the other hand, a decrease of $18.5 \%$ to $17.5 \%$ is observed by fixing the temperature at $60{ }^{\circ} \mathrm{C}$ and increasing the duration from $29 \mathrm{~min}$ to $155 \mathrm{~min}$ (Figure 5).

The 3D response surface (Figure 4) and the 2D contour diagram (Figure 5) are usually the graphical representations of the regression equation. This representation shows the relative effects of the variable when the remaining variable is held constant.
They are used to find the optimal values of the process parameters (Table 5). There is a correlation between TPC yield, and antioxidant activity of extract suggests that phenolic compounds are responsible for the antioxidant activity of these extracts. Indeed this demonstrated in several previous woks ${ }^{34,38}$.

The antioxidant activity of methanolic extracts measured by the free radical DPPH is compared to a synthetic antioxidant BHT. The percentage inhibition of the free radical by the BHT at a concentration of $0.001 \mathrm{~g} / \mathrm{L}$ is $15 \%$, compared to $21 \%$ for the methanolic extract obtained at $60{ }^{\circ} \mathrm{C}$ and $29 \mathrm{~min}$. This means that methanolic extracts have antioxidant activity comparable to that of a synthetic antioxidant $\mathrm{BHT}$, and this is demonstrated in several previous works ${ }^{39}$. Reducing the power of methanolic extracts was between 2.575 and 2.785 (for the methanolic extract obtained at $26^{\circ} \mathrm{C}$ and $92 \mathrm{~min}$, and $60{ }^{\circ} \mathrm{C}$ and $155 \mathrm{~min}$ respectively). Reducing the power of ascorbic acid at a concentration of $0.8 \mathrm{~g} / \mathrm{L}$ was 2.67 , compared to 2.745 for the methanolic extract obtained at $60{ }^{\circ} \mathrm{C}$ and $29 \mathrm{~min}$. 


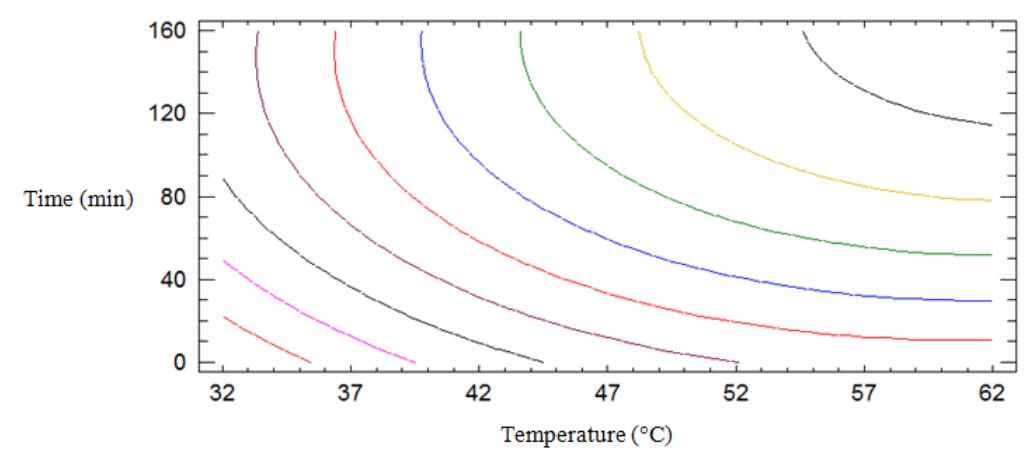

Yield (mg EAG/g MS)

\section{0}

700

740

$-780$

$-820$

-860
$-\quad 900$

900
-940

- 980

- 1020

$-1060$
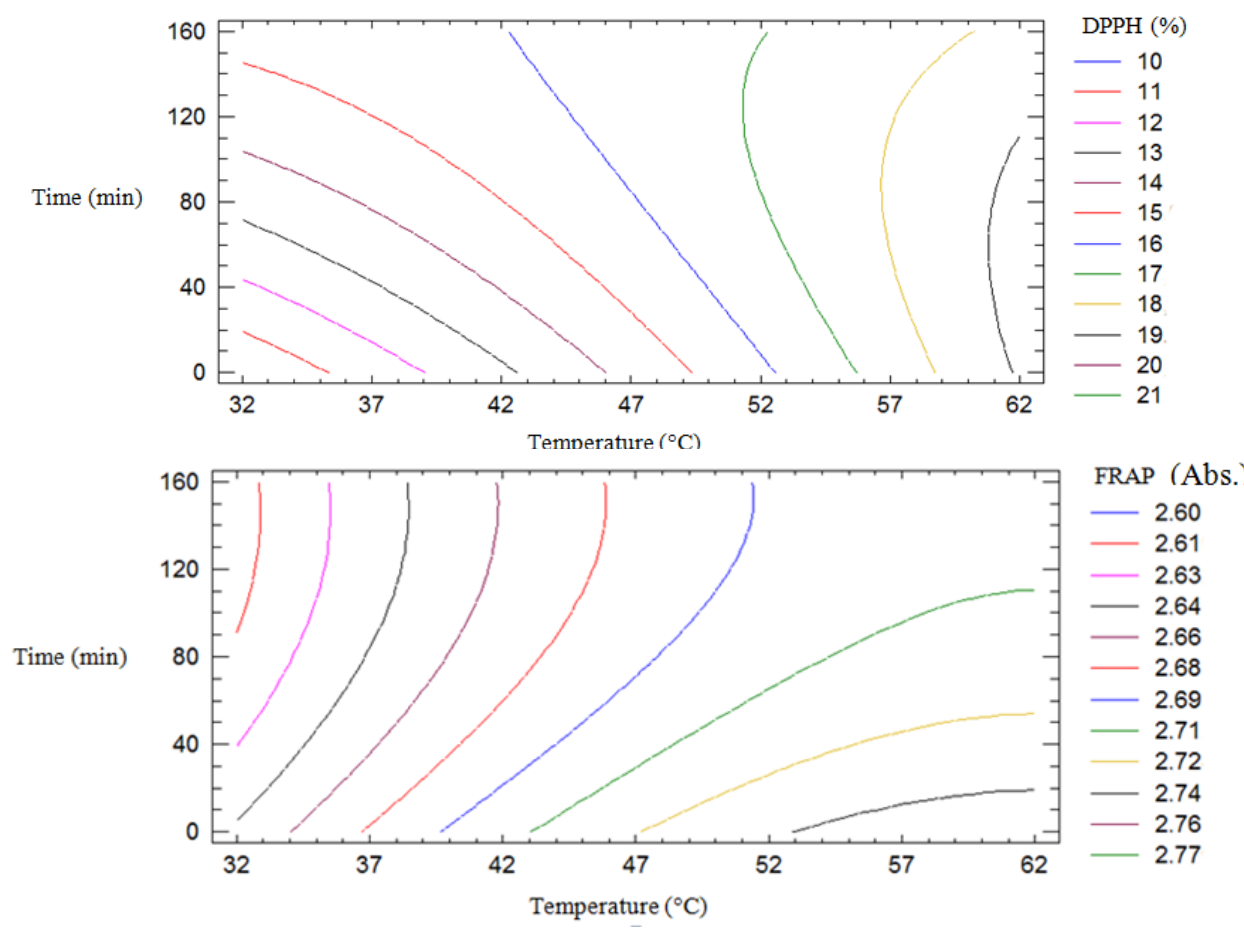

Figure 5. Contours of Estimated Surface Responses of TPC, DPPH and FRAP

Table 5. Optimal decoction parameters.

\begin{tabular}{|l|c|c|c|}
\hline & Dependent variables & Temperature $\left({ }^{\circ} \mathrm{C}\right)$ & Time $(\mathrm{min})$ \\
\hline TPC (mg EAG/g MS) & 1052 & 66 & 181 \\
\hline DPPH (\%) & 21 & 66 & 24 \\
\hline FRAP (Abs.) & 2.75 & 63 & 3 \\
\hline
\end{tabular}

\section{Conclusion}

The objective of our study is to evaluate the availability of polyphenolic compounds in the methanolic extracts of the skin of table grapes grown in Morocco and their antioxidant power. It was found that the extract obtained at $60{ }^{\circ} \mathrm{C}$ for $29 \mathrm{~min}$ had the highest antioxidant capacities $(21 \%)$ and $905.15 \mathrm{mg}$ EAG / g MS of the total polyphenols. However, the extract obtained at $60^{\circ} \mathrm{C}$ for $155 \mathrm{~min}$ had a TPC yield of $1042.05 \mathrm{mg}$ EAG / g MS and an antioxidant capacity of $16.96 \%$. This may be due to the thermal degradation of TPCs. A significant relationship between antioxidant activities and total phenolic content is found, indicating that phenolic compounds are responsible for the antioxidant capabilities of these extracts. By these results, we can conclude that the extracts of the grape skins represent an interesting source of phenolic compounds with antioxidant properties which would interest the pharmaceutical and food industries.

\section{References}

1- I. S. Arvanityoannis, D. Ladas, A. Mavromatis, Potential uses and applications of treated wine waste: a review, Int J Food Sci Tech, 2006, 41, 475-487

2- $\quad$ L. Andres, F. Riera, R. Alvarez, Recovery and concentration by electrodialysis of tartaric acid from fruit juice industries wastewaters. J Chem Technol Biot, 1997, 70, 247. 
3- M. C. Peixoto, M.I. Dias, M. J. Alves, R.C. Calhelha, L. Barros, S. P. Pinho, I. C.F.R. Ferreira, Grape pomace as a source of phenolic compounds and divers boctiv properties, food Chem., 2018, 253, 132-138.

4- L. Zhang, M.T. Zhu, T. Shi, C. Guo, Y. S. Huang, Y. Chen, M.Y. Xie, Recovery of dietary fiber and polyphenol from grape juice pomace and evaluation of their functional properties and polyphenol compositions, Food and Func, 2016, 8, 341-351.

5- D. Kammerer, A. Claus, R. Carle, A. Schieber, J. Agric. Food Chem., 2004, 52, 4360-4367

6- C. Santos-Buelga, A. Scalbert, J. Sci. Food Agric., 2000, 80, 1094-1117.

7- A. Moure, J. Cruz, D. Franco, J. M. Dominguez, J. Sineiro, H. Dominguez, M. J. Nunez, J. C. Parajo, Food Chem., 2001, 72, 145-171.

8- $\quad$ S. Ray, D. Bagchi, P. Lim, M. Bagchi, M. Gross, C. Kothari, G. Preuss, S. Stohs, Res. Commun. Mol. Pathol. Pharmacol., 2001, 109, 165-197.

9- A. Alonso, D. Guillean, C. Barroso, B. Puertas, A. Garcia, J. Agric. Food Chem., 2002, 50, 5832-5836.

10- W. Yi, J. Fischer, C.C. Akoh, J. Agric. Food Chem., 2005, 53, 8804-8812.

11- Y. Miyake, A. Murakami, Y. Sugiyama, M. Isobe, K. Koshimizu, K. Ohigashi, J. Agric. Food Chem., 1999, 47, 3151-3157.

12- J.C. Stoclet, T. Chataigneau, M. Ndiaye, M.H. Oak, J. El Badoui, M. Chataigneau, B. Valerie, K. Schini, Eur. J. Pharmacol, 2004, 500, 299313.

13- O.I. Aruoma, Food Chem. Toxicol., 1994, 32, 671-683.

14- A. Scalbert, G. Williamson, J. Nutr., 2000, 130, 2073-2085.

15- W.R. Leifert, M.Y. Abeywardena, Nutrition Research, 2008, 28, 729-737

16- C. Ramassamy, Eur. J. Pharmacol, 2006, 545, 51-64.

17- I. M. Valente, M.R.G. Maia, N. Malushi, H. M. Oliveira, L. Papa, J.A. Rodrigues, A.J.M. Fonseca, A.R.J. Cabrita, Profiling of phenolic compounds and antioxidant properties of European varieties and cultivars of Vicia faba L. Pods, Phytochemistry, 2018, 152, 223-229

18- B. Uttara, A. V. Singh, P. Zamboni, R. T. Mahajan, oxidative stress and neurodegenerative diseases: A review of upstream and downstream antioxidant therapeutic options, Curr Neuropharmacol., 2009, 7 (1), 65-74.

19- I. Soural, N. Vrchotová, J. Tříska, J. Balík, Š. Horník, P. Cuřínová, J. Sýkora, Molecules, 2015, 20, 6093-6112.
20- D. Pintac, T. Majkie, L. Torovic, D. Oreie, I. Beara, N. Simin, N. Dukie, M. Lesjak, solvent selection for efficient extraction of bioactive compounds from grape pomace, Ind Crop Prod, 2018, 111, 379-390.

21- A. Ojeil, N. El Darra, Y. El Hajj, P. Bou Mouncef, T. J. Rizk, R. G. Maroun, LSJ, 2010, $11,2$.

22- S. Hogan, L. Zhang, J. Li, B. Zoecklein, K. Zhou, Food Sci. Technol, 2009, 42, 1269-1274.

23- M.S. Blois, Nature, 1958, 181, 1199-1200

24- W. Brand, M.E Cuvelier, C. Berset, Food Sci. Technol, 1995, 28, 25-30

25- B.M. Lue, N. S. Nielsen, C. Jacobsen, L. Hellgren, Z. Guo, X. Xu, Food Chem., 2010, 123, 221-230.

26- B.S. Maataoui, A. Hmyene, S. Hilali, LSJ, 2006, 7,1 .

27- M. Oyaizu, The Japanese Journal of Nutrition and Dietetics, 1986, 44, 07-315

28- M. Haddoudi, H. Mellouk, B. Bejjany, A. Dani, K. Digua, Les Technologies de Laboratoire, 2014, 8, 36.

29- M. SolaymanHossain, M. Sohanur Rahman, A. H. M. RahmatullahImon, S. Zaman, A. S. M. B. Alam Siddiky, M. Mondal1, A. Sarwar, T. B. Huq, B. C. Adhikary, T. Begum, A. Tabassum, S. Alam, M. M. Begum, Clinicalphytoscience, 2016, 2, 10.

30- L. Lazar, Talmaciu A.L., Volf I., Popa V.I., Ultrason. Sonochem., 2016, 32, 191-197.

31- A. Gambuti, R. Capuano, L. Lecce, M. G. Fragasso, L. Moio, Vitis, 2009, 48, 193-200.

32- J. Dai, R.J. Mumper, Molecules, 2010, 15, 7313-7352.

33- H. Mellouk, A. Meullemiestre, Z. MaacheRezzoug, B. Bejjany, A. Dani, S.A. Rezzoug, J Clean Prod., 2016, 112, 4398-4405.

34- D. Karou, M.H. Dicko, J. Simpore, A.S. Traore, AJB, 2005, 4(8), 823-828.

35- J. Yang, K.J. Meyers, J.V.D. Heide, R.H. Liu, J. Agric. Food Chem., 2004, 52(22), 6787-6793

36- R.A. Ouedraogo, M. Koala, C. Dabire, A. Hema, V.B.E.J.T. Bazie, L.P. Ouattara, C. Gnoula, E. Pale, R.H.C. Nebie, IJBCS, 2015, 9(1), 281-291.

37- N. Aoussar, R. Manzali, I. Nattah, N. Rhallabi, P. Vasiljevic, M. Bouksaim, A. Douira, N. Manojlović, F. Mellouki, JMES, 2017, 8(6), 1968-1976.

38- C. Sarikurkcu, M.S. Kocak, M. Calapoglu, C. Ocal, B. Tepe, J Funct Foods, 2016, 24, 11-17.

39- M. Hebi, M. Eddouks, Rev Phytother, 2016, 14(1), 17-22. 